\title{
PROJETO HISTÓRIAS DE VIDA: \\ DESENVOLVENDO PESQUISA ACADÊMICA NA GRADUAÇÃO EAD \\ E O PROCESSO DE FORMAÇÃO E (RE)CONHECIMENTO DA DOCÊNCIA
}

\author{
Rodrigo Lemos Simões ${ }^{1}$
}

\begin{abstract}
Resumo: Este texto aborda, em um primeiro momento, aspectos da educação a distância no Brasil, a partir de dados estatísticos que demonstram algumas das especificidades da oferta de cursos de graduação nesta modalidade de ensino. Posteriormente, apresentamos elementos específicos dos documentos institucionais a respeito da formação dos estudantes em uma IES da região metropolitana de Porto Alegre, a sua relação com a educação a distância, dando destaque ao que é dito nos textos a respeito da pesquisa enquanto componente indissociável da formação profissional. Finalizamos com a apresentação de um projeto de pesquisa desenvolvido, especificamente, para atender às necessidades formativas dos estudantes da modalidade de ensino em questão.
\end{abstract}

Palavras-chave: Educação a distância, pesquisa acadêmica, histórias de vida

\section{PROJECT LIFE STORIES: DEVELOPING ACADEMIC RESEARCH IN EAD GRADUATION \\ AND THE TRAINING PROCESS AND (RE) KNOWLEDGE OF TEACHING}

\begin{abstract}
First of all, this paper approaches aspects of distance education in Brazil since statistics demonstrate some of the specificities which undergraduate courses offer in this teaching mode. Subsequently, it is presented specific elements of institutional documents regarding training of students in an IES of the Metropolitan area of Porto Alegre, its relationship to distance education, enhancing what it is said in the texts about the research as an indissociable component of professional training. We conclude with the presentation of a research project specifically designed to meet the educational needs of students of the educational mode in question.

Key-words: Distance education, academic research, life histories
\end{abstract}

\section{ASPECTOS DA EDUCAÇÃO A DISTÂNCIA NO BRASIL}

Neste texto, iremos apresentar, de forma sintética, alguns dos aspectos históricos da educação a distância no Brasil, o processo de desenvolvimento da oferta e alguns dados estatísticos atuais sobre a situação em que se encontra esta modalidade de ensino. Posteriormente, apresentaremos dados sobre a oferta da EAD na Universidade Luterana do Brasil (ULBRA), dando enfoque ao Curso de Licenciatura de História oferecido na modalidade a distância pela IES. Concomitante, apresentaremos excertos de documentos institucionais que apontam a relevância e a necessidade da formação integral dos estudantes, especialmente no que se refere ao compromisso assumido em relação à pesquisa acadêmica, mais especificamente sobre a pesquisa em nível de graduação. No momento seguinte, apresentaremos um projeto de pesquisa em andamento, proposição feita pelo Curso de História na modalidade EAD, com a finalidade de integrar e de

\footnotetext{
${ }^{1}$ Licenciado e Mestre em História, Doutor em Educação, Professor Adjunto e Coordenador do Curso de Licenciatura em História da Universidade Luterana do Brasil nas modalidades presencial e a distância.
} 
difundir a pesquisa acadêmica entre os estudantes das diversas licenciaturas oferecidas pela IES, através da temática das histórias de vida de professores da educação básica.

De modo geral, a educação a distância tem percorrido uma trajetória significativa ao longo do tempo. Em diversos países, esta modalidade de ensino foi adotada com diferentes finalidades, em cursos voltados à educação escolar, à formação profissional e ao aperfeiçoamento em áreas específicas, seja através de correspondência, rádio, televisão, seja por computador via Internet. No Brasil, a educação a distância percorreu, basicamente, os mesmos caminhos seguidos por outros países neste processo de difusão do conhecimento, sendo que, desde o início do século $\mathrm{XX}$, podem ser verificadas iniciativas que promoveram de formas distintas a formação pessoal através desta modalidade, especialmente voltada ao letramento de jovens e adultos (ALVES, 2011).

Contudo, foi no governo do presidente Fernando Henrique Cardoso que, no ano de 1996, foram estabelecidas as bases legais da educação a distância no Brasil, através da Lei de Diretrizes e Bases da Educação Nacional nº 9.394 (LDB/1996). Naquele momento, estabeleceu-se a regulamentação da modalidade de ensino, especialmente no que tange as IES em relação ao credenciamento, às autorizações de funcionamento, ao reconhecimento, à renovação e às equivalências entre as modalidades. Soma-se a isso uma série de normatizações referentes ao papel do Poder Público na promoção, difusão e controle sobre a educação a distância no país.

Pode-se dizer que, a partir da década de 1990, mediante o desenvolvimento e difusão das novas tecnologias da informação, a educação a distância passou a ocupar um espaço de destaque nas universidades brasileiras. Conforme destaca (HERMIDA, 2006, p. 167):

\footnotetext{
Nesse novo contexto, as instituições de ensino superior passaram a sofrer transformações. Os processos de crescimento, expansão, diversificação, especialização e diferenciação dos sistemas de educação superior, associados à generalização da informática e das telecomunicações estimuladas pela tendência na modernização produtiva e a globalização dos mercados, deram espaço à emergência de novos cenários e modalidades de ensino. O desenvolvimento acelerado das ciências, associado ao das NTIC trouxe, em consequência, uma diversidade de aplicações que, ao serem utilizadas em educação, ampliaram horizontes de atuação e intensificaram a produção de novos conhecimentos. Dentre as modalidades de atuação que mais cresceram temos a Educação à Distância (EAD).
}

Porém, um dos marcos mais significativos relativos ao ensino superior na modalidade a distância no país está a criação da Universidade Aberta do Brasil (UAB) 
pelo Ministério da Educação no ano de 2005, posteriormente regulamentado pelo Decreto $\mathrm{n}^{\circ}$ 5.800, do Presidente Luiz Inácio Lula da Silva, de 8 de junho de 2006. Conforme Hernades (2017, p. 6), esta iniciativa que mobiliza diferentes níveis governamentais e instituições públicas de ensino "surge em um período em que os novos meios de informação e comunicação, sobretudo a internet, estavam disponíveis, possibilitando as interações professor-estudante e estudante-estudante, na rede”. Já Costa e Pimentel (2009) destacam que a UAB possui três pilares fundamentais de sustentação de sua macroestrutura, o MEC, com a condução central do processo, as IES com a oferta dos cursos na metodologia a distância e os municípios e estados sediando os polos de apoio presencial.

Assim, o Sistema Universidade Aberta do Brasil, ao englobar uma rede de cooperação entre Governo Federal, Estados e municípios, busca atender à demanda por formação em nível superior daquelas pessoas com dificuldade de acesso, tanto em relação ao deslocamento do interior para as cidades universitárias, quanto em relação às dificuldades de conexão à Internet nos seus municípios de origem. Nos polos, é encontrada a infraestrutura adequada para atendimento aos estudantes, com conexão de Internet, laboratórios, bibliotecas e salas de tutoria. Além disso, Costa e Pimentel (2009, p. 84) salientam que a relação estabelecida junto às instituições públicas de ensino superior, "responsáveis pela elaboração do projeto pedagógico, pela gestão acadêmicoadministrativa dos cursos e pela certificação dos alunos", busca garantir a melhor adequação do processo formativo, contextualizando-o diante das novas tecnologias da informação e das demais necessidades inerentes à prática docente na escola básica. Destacam, ainda, que os processos decisórios da UAB dão-se através de fóruns nacionais e regionais de coordenadores e de fóruns de área, em que são ampliadas as discussões sobre os diferentes cursos por ela oferecidos. Para Basso e Prado (2013, p. 3):

Dentro de uma lógica emancipatória de combate às desigualdades, sob a égide da interiorização e democratização da educação superior pública, a criação da UAB se apresenta, no contexto brasileiro, como um novo modelo de universidade dentro do campo da educação. A noção de "campo" aqui é como a definida por Pierre Bourdieu, "um espaço relativamente autônomo, esse microcosmo dotado de suas próprias leis. Se, como o macrocosmo, ele é submetido a leis sociais, essas não são as mesmas" (BOURDIEU, 2004, p. 20), onde os agentes agem de acordo com um habitus, que é uma maneira de interiorizar seu modo de agir ocupando posições estabelecidas dentro dos campos sociais. Bourdieu se refere a campo educacional como sendo o conjunto de escolas, professores, alunos, etc., e sendo assim, a instância da produção do conhecimento. E, portanto, a UAB se configura como um novo microcampo no âmbito do campo da 
educação que, dentro da lógica que lhe é pertinente, solidifica outra modalidade de ensino, a educação à distância.

Ao incorporarem a educação a distância como possibilidade de formação em nível superior, as IES ampliaram o leque de oferta de cursos, reduzindo custos e democratizando o ensino, uma vez que abriram o acesso à universidade a uma parcela significativa da população que, historicamente, se vira alijada do acesso ao ensino superior. A flexibilização do tempo de estudo, os materiais didáticos produzidos especificamente para este fim, associados aos custos reduzidos, são os maiores benefícios da educação a distância para a classe trabalhadora - aspectos pontuais em que o ensino formal inviabilizava a sua participação. Soma-se a isso a proliferação dos polos das universidades públicas e privadas que passaram a levar a educação superior aos locais mais remotos do território nacional.

Em relação aos números do ensino superior no país, a Síntese de Indicadores Sociais (SIS), realizada pelo IBGE, no ano de 2014, aponta que a escolaridade média da população aumentou entre os anos de 2004 e 2013. Em relação ao ensino superior, os dados apresentados referem-se à parcela da população que se encontra entre os 25 e os 34 anos de idade. Este segmento passou de $8,1 \%$ para $15,2 \%$ no período e, ainda assim, os dados apontam que o percentual é menor quando comparado aos países da Organização de Cooperação e Desenvolvimento Econômico (OCDE). No período em questão, os estudantes com os maiores rendimentos diminuíram nas universidades públicas $(38,8 \%)$ e privadas $(43,0 \%)$, aumentando o acesso de estudantes dos demais estratos de rendimento, inclusive dos mais pobres. No ano de 2004, o documento aponta que apenas 1,7\% dos estudantes do ensino superior pertencentes aos $20 \%$ com os menores rendimentos frequentavam universidades públicas; já, no ano de 2013, o número chega a 7,2\%.

Ao analisarmos os indicadores referentes à situação da educação no Brasil, divulgados pela Organização de Cooperação e Desenvolvimento Econômico (OECD), no ano de 2015, constatamos que, embora o investimento governamental, em instituições públicas, tenha aumentado em todos os níveis educacionais, entre os anos de 2005 e 2012, o gasto anual por aluno de instituições públicas caiu 7\% na educação superior. Ainda assim, a parcela da população com diploma de ensino superior no País vem aumentando, mesmo que em um ritmo lento. Segundo o documento:

São apenas 4 pontos percentuais de diferença entre o percentual de diplomados do ensino superior para a faixa etária de 55 a 64 anos e a faixa 25 a 34 anos de idade. Entre 2009 e 2013, a parcela da 
população com idade entre 25 e 64 anos que concluiu o ensino superior aumentou 3 pontos percentuais, alcançando 14\% em 2013. Esse nível de conclusão do ensino superior esteve bem abaixo da média OCDE de $34 \%$, assim como abaixo das taxas de outros países latino-americanos, como o Chile (21\%), Colômbia (22\%), Costa Rica (18\%) e México (19\%). (OECD Indicators: 2015, p. 1-2)

O Censo participativo EAD.BR 2016 da Associação Brasileira de Educação a Distância (ABED), realizado junto a 1.303 instituições colaboradoras, demonstra a presença da oferta desta modalidade de ensino em todos os Estados do País, sendo a maior concentração nas regiões Sul e Sudeste. O Estado de São Paulo apresenta o maior número de instituições, seguido pelo Paraná e Rio de Janeiro. O Rio Grande do Sul, quarto colocado neste ranking, aparece com a oferta da modalidade em vinte e nove IES. Em nível nacional, a distribuição das sedes destas instituições encontra-se, em sua maioria, nas capitais e no distrito federal, $65 \%$, ao passo que $35 \%$ delas ficam no interior. As instituições educacionais públicas federais e estaduais, além daquelas formadas pelo Sistema Nacional de Aprendizagem (SNA), somam o maior índice de interiorização através dos polos de ensino. A este respeito, o documento destaca que:

\begin{abstract}
A localização dos polos também revela uma forte interiorização e atendimento amplo por todo o país. Entre os respondentes, 64\% instituições que oferecem educação a distância contam com polos de apoio presencial para atender seus alunos. $O$ total de polos contabilizado pelo Censo EAD. BR 2016 é de 5.746, dos quais 992 estão em capitais e 3.661, no interior. Não há informações sobre 1.093 instalações. A quantidade total de polos é inferior à contabilizada em 2015. Ao consultar os dados históricos, verificamos que uma instituição que alegou ter mais de 800 polos em 2015 não respondeu o Censo de 2016. Sendo assim, podemos afirmar que não há constatação de redução de polos no Brasil.
\end{abstract}

Em termos de matrículas, o mesmo documento aponta um total de 561.667 alunos em cursos regulares totalmente a distância, em todos os níveis acadêmicos. Em relação ao ensino superior, as especializações lato sensu lideram em termos de oferta, com 1.098 cursos. Nos cursos de graduação, por área do conhecimento, as ciências humanas lideram com uma oferta de 250 cursos, seguida das ciências sociais aplicadas com a oferta de 218 cursos. Lideram as licenciaturas com um total de 210 ofertas. Evidencia-se, pelos dados obtidos no censo, que, em termos gerais, a educação a distância atende os públicos masculino e feminino em proporções relativamente equivalentes, ainda que exista uma leve tendência de aumento no número de estudantes 
composto pelo público feminino. Contudo, o censo salienta que, dependendo dos cursos e das instituições, a relação entre o público feminino e o público masculino pode se modificar significativamente.

A questão etária é outro elemento analisado no documento que aponta uma "alta incidência de alunos após a idade típica da graduação" na educação a distância em relação aos cursos presenciais. Neste caso, temos que, em 37\% dos cursos, a maior concentração etária de alunos está entre 31 e 40 anos. A esta informação segue o fato de que, na educação a distância, o percentual de alunos trabalhadores é exponencialmente superior aos cursos semipresenciais e presenciais, sendo que, em 30\% das instituições que participaram do censo, mais de $75 \%$ dos alunos estudam e trabalham.

Já o Censo da Educação Superior divulgado pelo INEP, no mês de agosto de 2017, apresenta o número de 2.985.644 ingressantes em cursos de graduação no Brasil, no ano de 2016. Destes, 843.181, ou seja, 28\% do total dos novos universitários ingressaram na educação à distância. Conforme o documento, no ano de 2006, a modalidade a distância representava pouco mais de $4 \%$ das matrículas de graduação, ao passo que, no ano de 2016, este número aumentou para mais de 1,4 milhão de alunos matriculados em cursos oferecidos na modalidade, o que representa 18,6\% dos alunos de graduação no país.

Por outro lado, verifica-se que o número de matrículas em cursos de graduação na modalidade presencial diminuiu 1,2\% entre 2015 e 2016, ao passo que, nos anos de 2014 e 2015, a modalidade a distância aumentou em mais de $20 \%$ o número de ingressantes. Dados apontados pela série histórica demonstram que, se entre os anos de 2006 e 2016 o número de ingressos variou positivamente 22,2\% nos cursos de graduação presencial, já, nos cursos oferecidos na modalidade a distância, o aumento foi de quase 4 vezes, ou seja, 297,3\%.

O documento aponta ainda que, ao contrário da modalidade presencial, em que, majoritariamente, lideram as matrículas em cursos de bacharelado, na modalidade de graduação a distância, destacam-se os cursos de licenciatura, em que o número de matrículas chega a 640.327 , ou seja, $42,1 \%$ do total de matriculados na modalidade. Os 3 maiores cursos de licenciatura no Brasil apurados no ano de 2016 são, respectivamente, Pedagogia, com 675.644 matrículas, Formação de Professor de Educação Física, com 185.554 matrículas, e Formação de Professor de História, com 87.789 matrículas.

Segundo o documento, o aluno que melhor caracteriza os cursos de licenciatura matriculados na modalidade é do sexo feminino e frequenta o curso superior em uma 
universidade. Ao contrário dos $85 \%$ dos estudantes de licenciatura de instituições públicas matriculados em cursos presenciais, quase $60 \%$ dos alunos de licenciatura da rede privada frequentam os cursos na modalidade a distância. No ano de 2016, o número de alunos que concluíram cursos de graduação, na modalidade presencial, teve aumento de 2,4\% em relação a 2015. Por outro lado, após um período de crescimento, observou-se que, nos cursos oferecidos na modalidade a distância, o número de alunos que concluíram cursos de graduação diminuiu 1,3\%, levando a diminuição da participação de 20,3\% em 2015 para 19,7\% em 2016.

\section{DADOS INSTITUCIONAIS E O CURSO DE HISTÓRIA EAD}

A metodologia da educação a distância teve início na Universidade Luterana do Brasil (ULBRA), no ano de 2000, momento em que se coloca, como meta institucional, a oferta da educação a distância e a ampliação da incorporação tecnológica ao ensino presencial. Contudo, foi, no ano de 2004, com a publicação, no Diário Oficial da União, da Portaria MEC $n^{\circ}$ 650/04, que a IES obteve seu credenciamento para a oferta de cursos nesta modalidade. Atualmente, nos 80 polos credenciados para oferta de cursos na modalidade, são oferecidos 20 Cursos de Graduação e 21 Cursos de Pós-Graduação em diferentes áreas do conhecimento. Neste sentido, destaca-se a abrangência nacional da modalidade a distância desenvolvida pela IES, abarcando todas as regiões brasileiras. Entre as diretrizes que norteiam a Política de Extensão, Pesquisa e Ensino da Universidade, destaca-se o seu compromisso em desenvolver "ações que articulem e retroalimentem a indissociabilidade entre a Extensão, a Pesquisa e o Ensino, como princípio para aprendizagens significativas e transformadoras”. (PDI, 2017, p. 57).

De modo geral, a política da Universidade para o ensino de graduação a distância fundamenta-se na integração entre ensino, extensão e pesquisa, sendo esta última guiada por diretrizes que visam garantir a ampliação do conhecimento científico e das práticas de pesquisa em todas as áreas do conhecimento em que a IES atua, a fim de garantir uma formação que associe qualidade acadêmica e profissional. Neste sentido, são produzidos diferentes tipos de materiais didáticos disponibilizados on line, tais como livros, artigos e videoaulas, além da interação entre professores, alunos e tutores. Soma-se a estes recursos os encontros presenciais em que ocorrem orientações e atividades diversificadas. As atividades a distância via web são desenvolvidas através do AVA - Ambiente Virtual de Aprendizagem como ferramenta básica. 
Ao destacar a utilização dos Ambientes Virtuais de Aprendizagem - AVAs, no processo de ensino-aprendizagem, Costa e Franco (2005) acrescentam que "um dos aspectos que mais diferencia a modalidade a distância da presencial é a ênfase dada na primeira ao trabalho autônomo". Para os autores, existem particularidades na utilização dos AVAs na medida em que, ao contrário de uma simples consulta à internet, os estudantes podem tornar-se produtores da informação. Já Pereira e França (2013, p. 79) destacam a importância de recursos tecnológicos como os AVAs no processo de construção do conhecimento. A possibilidade de se obter e compartilhar informações de forma simultânea reforçam suas possibilidades como ferramenta de ensino que pode ser utilizada na construção de conhecimentos individuais e coletivos. A "possibilidade de gerenciamento das informações, a postagem de materiais de estudo seja pelo professor ou pelo aluno e ainda a comunicação (síncrona e assíncrona) via fórum, chat, etc" aparecem como algumas das vantagens para a educação. Neste sentido, os autores acrescentam que os AVAs podem ser:

[...] uma ferramenta capaz de dar novas possibilidades para o processo de ensino-aprendizagem como criação de espaço para aulas virtuais, disponibilidade de tempo e espaço para ampliar as discussões. Uma vez que estes ambientes permitem aos usuários discutir problemáticas, trocas individuais e coletivas de informações tornando assim um espaço de pesquisa e criação de produtos ao mesmo tempo em que se desenvolve. Os ambientes virtuais de aprendizagem permitem aos participantes fornecer informações, trocar experiências, discutir problemáticas e temas de interesses comuns, desenvolverem atividades colaborativas para compreender seus problemas e buscar alternativas de solução [...] são espaços organizados e planejados que podem nos dar possibilidades de alteração de hábitos de trabalho, viabilizando o diálogo, a reflexão e o registro crítico de percursos. Representando assim não apenas recursos tecnológicos, mas ferramentas que possibilitem a construção de conhecimentos. (PEREIRA; FRANÇA: 2013, p. 80)

No que tange ao Curso de Licenciatura em História oferecido pela IES na modalidade a distância, hoje, presente nas cinco regiões do país, foi autorizado pelo Conselho Universitário, através da Resolução 007, de 16 de maio de 2013, tendo seu reconhecimento obtido pela Portaria/MEC n 729, de 14 de julho de 2017. Entre os objetivos do curso, está a formação do aluno para a prática docente, de forma interdisciplinar, em que as experiências de pesquisa e as práticas pedagógicas façam-se presentes nos diferentes momentos da sua trajetória acadêmica, contribuindo, assim, para a formação de profissionais capacitados a exercer de forma qualificada o ensino de história, planejando e desenvolvendo suas práticas de acordo com as necessidades locais 
e regionais. Em relação ao desenvolvimento da pesquisa enquanto componente de formação obrigatória nos cursos de graduação, o Projeto Pedagógico do Curso de História destaca que o processo de organização curricular para os cursos, na modalidade a distância, devem fundamentar-se em diretrizes que promovam a pesquisa individual e coletiva como instrumento de conhecimento reflexivo e compreensivo da realidade. Nesta mesma direção, temos que a missão estabelecida pelo curso de história consiste em:

[...] formar cidadãos preparados para enfrentar os desafios da realidade em que estão inseridos, bem como proporcionar a dimensão valorativa da educação, voltada para o desenvolvimento da cidadania, com ênfase em princípios morais e éticos. Para cumprir essa missão, o Curso de História estimula o aluno a conhecer, em profundidade, os processos históricos, procurando capacitá-lo a atuar criticamente na docência do Ensino Fundamental e Médio e a desenvolver atividades de pesquisa e extensão relacionadas às novas demandas sociais e do mercado de trabalho. (Projeto Pedagógico do Curso de História: 2016, p. 27).

Ao longo dos anos de docência no ensino superior e, mais especificamente, a partir do ingresso na educação a distância, estabelecemos como metas o estudo e o desenvolvimento de metodologias capazes de potencializar a interação entre estudantes e professores, redimensionando os recursos didáticos disponíveis e criando novas possibilidades de ensino e aprendizagem. Mais recentemente, voltamos nossas atenções para um local específico deste processo, o desenvolvimento da pesquisa científica. $\mathrm{O}$ interesse no tema decorre do fato de ser esta uma referência constante do discurso acadêmico em relação a formação discente.

\section{PESQUISA ACADÊMICA E O (RE) CONHECIMENTO DA PROFISSÃo DOCENTE}

Damos continuidade a este relato a partir de uma experiência desenvolvida no âmbito do Curso de Licenciatura em História em que o desenvolvimento da pesquisa acadêmica organiza-se a partir do Grupo de Pesquisa, cadastrado na base de dados do CNPq, com o nome de Patrimônio Cultural e Identidades, voltado às seguintes Linhas de Pesquisa: Identidades e Práticas Culturais; Memória e Preservação de Bens Culturais; Pedagogias e políticas da diferença. Foi, neste contexto, que demos início ao projeto de pesquisa História de vida e autoformação: os profissionais da educação básica e as narrativas de si, como parte da proposta de fomento à pesquisa do Curso de 
História, estando alinhado à Linha de Pesquisa: Identidades e Práticas Culturais. Nosso objetivo, ao propor este projeto, foi, principalmente, o de difundir e desenvolver a capacitação para a pesquisa acadêmica junto aos estudantes do Curso de História e dos demais Cursos de Licenciatura oferecidos pela IES, na modalidade a distância.

Pesquisas sobre histórias de vida de professores abrem espaço ao pensar sobre si em direção à autoformação, possibilitando um redimensionamento das experiências pessoais e profissionais. Para os estudantes, trata-se da oportunidade de conhecer as experiências e histórias dos docentes e, a partir disso, pensarem sobre si mesmos como futuros professores. A participação no projeto foi aberta aos estudantes das diversas licenciaturas para que estes pudessem conhecer mais sobre a profissão a partir do desenvolvendo de entrevistas com professores das redes públicas de ensino. Diante da reestruturação curricular promovida pela IES no ano de 2017, estabelecemos que o projeto deveria estar vinculado às disciplinas/componentes curriculares de formação pessoal e profissional dos Cursos de Licenciatura, para que, também, através das aulas, se pudesse trabalhar a temática do conhecimento profissional e da revalorização da profissão docente, chamando a atenção para a dimensão pessoal na autoformação do professorado.

Pensamos que a proposta justificava-se na medida em que os estudos a respeito do professorado são de grande importância para o conhecimento da profissão, servindo como um motor de promoção de práticas e saberes capazes de ressignificar olhares e conceitos sobre o magistério, a escola e a educação. Além disso, e como mencionamos anteriormente, estabelecemos como princípio a necessidade de iniciar os estudantes na prática da pesquisa acadêmica a partir de uma proposta que se quer inovadora, sob o ponto de vista de sua inserção no cenário local em que se desenvolverão os estudos. Acreditamos que podemos, efetivamente, promover o estreitamento do diálogo entre escola e universidade através da pesquisa, cabendo à universidade estabelecer os vínculos entre os saberes acadêmicos e os saberes e vivências dos professores em diferentes contextos. Assim, tendo como enfoque as Histórias de vida e autoformação dos profissionais da educação básica e as narrativas que fazem de si, propusemos o seguinte problema de pesquisa:

- É possível trabalhar a ressignificação e valorização do magistério na educação básica a partir das representações feitas pelos professores a respeito de si enquanto profissionais da educação, dando ênfase às suas falas sobre os seus processos formativos, os conhecimentos que têm sobre da profissão, a escola e a educação de forma abrangente, bem como sobre o papel que desempenham no cenário educacional local? 
Esta é, sem dúvida, uma das questões fundamentais que permeia a profissão docente e a formação para a docência na atualidade. Temos a ciência da necessidade dos futuros profissionais em se constituir profissionalmente como docentes e pesquisadores, associando à sua prática o entendimento e a reflexão crítica das circunstâncias sociais, econômicas, políticas e culturais sob a qual está inserida a escola e o professorado. Foi pensando nisso, e tendo por base a Resolução CNE/CES n ${ }^{\circ}$ 13, de 13 de março de 2002, que estabelece as diretrizes curriculares para os Cursos de História, além da Portaria Inep n ${ }^{\circ}$ 266, de 02 de junho de 2014, Enade/História, e a Resolução MEC/CNE nº 2, de $1^{\circ}$ de julho de 2015, que define as Diretrizes Curriculares Nacionais para a Formação Inicial e Continuada em Nível Superior de Profissionais do Magistério para a Educação Básica, que estabelecemos para o projeto os objetivos de conhecer a narrativa dos professores da educação básica a respeito da sua realidade sociocultural, o que pensam sobre o trabalho educativo, o processo formativo e a formação continuada, as suas práticas pedagógicas e o papel a ser desempenhado pelos profissionais da educação na sociedade atual.

Além disso, interessou-nos problematizar e interpretar, por meio de fontes e linguagens diversas, as múltiplas dimensões das experiências formativas e profissionais destes professores. Trabalhando de forma interdisciplinar, articulando a problemática da formação docente e do constituir-se enquanto professor com outras áreas do conhecimento, acreditamos poder atuar junto à comunidade escolar de forma bem abrangente, no sentido de identificar questões e problemas socioculturais presentes no contexto da educação básica. A partir disso, proporemos o diálogo entre a comunidade escolar e os diferentes segmentos da sociedade, no sentido de promover a valorização da escola, da educação e dos profissionais do magistério, atuando de forma crítica e investigativa na proposição de ações que levem em consideração temas específicos e relevantes à comunidade escolar, promovendo relações de cooperação entre a instituição educativa, a família e a comunidade.

A fim de buscarmos subsídios teóricos ao trabalho, recorremos a Nóvoa (1992) quando este desenvolve sua reflexão a respeito da carreira docente, ressaltando que vivemos um momento em que a retórica sobre o papel fundamental dos professores como construtores da sociedade do futuro encobre a intencionalidade de acobertar problemas graves relacionados à educação, especialmente, no que diz respeito à pobreza das políticas públicas relativas à formação inicial e continuada dos docentes. Efetivamente, o que se tem percebido, ao longo das últimas décadas, é a pauperização 
das práticas pedagógicas, consumada através do enrijecimento dos modelos curriculares, e o excesso de um discurso científico-educacional, que pouco tem dado voz aos profissionais do magistério para que exponham suas percepções a respeito do cenário educacional, das possibilidades de trabalho e da formação continuada, da gestão da escola e do ensino, dos estudantes, entre outras.

Neste sentido, Segovia (2014) adverte que a capacidade crítico-reflexiva do professorado proporciona a produção de conhecimentos sobre suas práticas, sendo a investigação narrativa o instrumento de elucidação e promoção da experiência e do saber acumulado que se integra ao conhecimento, fazendo-se público na narração. Trata-se da possibilidade não só do pensar sobre si enquanto profissional do magistério, sua trajetória formativa e prática docente, como também possibilitar o conhecimento da profissão através da socialização de experiências.

Já Josso (2006) salienta que o trabalho sobre relatos de história de vida constitue um dos sinais da emergência de novos paradigmas que se fundamentam sobre a subjetividade explicitada de forma consciente, uma vez que abordam um tipo de conhecimento que valoriza a reflexividade produzida a partir de vivências singulares.

Também nos interessamos pelas pesquisas de Tardif (2000, 2002, 2007), a partir das quais demonstra que os conhecimentos prévios são de grande importância para as experiências de formação, orientando seus resultados. Para esse autor, existem filtros cognitivos, sociais e afetivos pelos quais são recebidas e processadas as informações. Como eles provêm da própria história de vida do indivíduo e de sua trajetória escolar, esses filtros permanecem fortes e estáveis ao longo do tempo.

Chamamos, ainda, a atenção para a emergência de novos paradigmas, em especial na área das ciências humanas, algo possível de ser verificado nas últimas décadas, sendo que, na área da pesquisa em educação, podem-se destacar os trabalhos desenvolvidos a partir das diferentes formas com que se apresentam os estudos culturais, especialmente aqueles em que a análise do conjunto da produção cultural de uma sociedade e o seu significado político tornam-se questões comuns, em que a busca do entendimento das ideias e comportamentos expressos nos textos e práticas em uma sociedade ganha relevo.

A este respeito, Silva (2006) acrescenta que os diferentes grupos sociais utilizam a representação para forjar a sua identidade e as identidades dos outros grupos sociais. Logo, as representações culturais são mais do que meros signos, elas criam sentidos e dão suporte às diferentes noções que os grupos sociais e culturais têm a respeito de si e 
dos demais. Portanto, em se tratando das análises culturais, as representações, identidades e o poder estão imbricados e devem ser entendidos nos processos de disputa que caracterizam a política de identidade, em que grupos diferentes exercem, outorgam ou reivindicam esse direito.

Em relação aos procedimentos metodológicos, propusemo-nos a desenvolver um trabalho de pesquisa que envolvesse a comunidade escolar em um processo de trabalho interdisciplinar, em que o contato com os entrevistados proporcionasse o conhecimento de distintos aspectos da profissão docente através das falas dos profissionais da educação. Neste sentido, o projeto foi direcionado aos professores de educação básica das redes públicas de ensino, a fim de dar voz a estes profissionais, buscando compreender o significado das suas práticas e discursos, seus projetos formativos e expectativas em relação à profissão. Propomo-nos a realizar uma releitura da inserção docente na escola e na comunidade em que esta está inserida, revalorizando o olhar a respeito do magistério e dos profissionais da educação através do conhecimento dos seus processos formativos, práticas e narrativas de si.

Neste sentido, a metodologia a ser empregada é de caráter qualitativo, através de entrevistas semiestruturadas, em que buscamos coletar material capaz de nos evidenciar tudo aquilo em que os professores acreditam e que carregam consigo como verdades a respeito da profissão, suas dúvidas, seus desejos e objetivos enquanto profissionais da área do ensino.

O instrumento a ser utilizado na pesquisa foi elaborado em conjunto, a fim de dar conta das diversidades sociais e regionais entre os participantes do projeto. Os estudantes/pesquisadores foram orientados a estabelecer contato com os entrevistados e agendarem um local para a pesquisa. Orientou-se, ainda, que buscassem um local não institucionalizado, ou seja, fora da escola e do horário de trabalho do entrevistado, a fim de evitar qualquer tipo de interferência no processo. Posteriormente, será dado início ao trabalho de identificação e categorização dos discursos que contrastam o ideal da profissão frente à realidade experienciada nas escolas de Educação Básica, à visão social sobre o magistério e seus profissionais, aos processos formativos, às práticas diárias inerentes à profissão, à autoformação e ao histórico anterior à docência.

Para esta etapa do trabalho, e levando em consideração os pressupostos atinentes à Análise Textual Discursiva (MORAES, 2007), especialmente naquilo que ela busca em termos de subsídios na análise do discurso, propomos que sejam destacados e desenvolvidos estudos sobre as falas que buscam redimensionar o ato educativo através 
de práticas e ações capazes de reafirmar o trabalho docente diante das diversas situações encontradas no dia a dia da profissão.

Segundo Goldim (2001), a caracterização da população a ser estudada e, quando for o caso, as técnicas de amostragem e os critérios de seleção, inclusão e exclusão utilizadas devem constar de forma explícita. Contudo, adverte o autor, nos estudos qualitativos, quando não é possível estabelece-los, devem ser apresentados os elementos necessários para caracterizar o volume de observações que serão realizadas. Assim, em relação à pesquisa que propusemos ser desenvolvida, estima-se que a população estudada será composta por sessenta professores da educação básica, trabalhadores das redes públicas de ensino dos Estados e municípios de abrangência dos polos de Educação a Distância da Universidade Luterana do Brasil (ULBRA). Neste sentido, não trabalhamos com vistas a um número amostral específico. Conforme Goldim (2001), quando não for possível apresentar o cálculo do tamanho da amostra, estabelecendo-o com base em estudos prévios, podem ser feitas estimativas de impacto ou efeito da intervenção ou de ocorrência do fator em estudo. Nossa estimativa teve por base o número de trinta sujeitos envolvidos como alunos/pesquisadores na pesquisa e a meta de que estes realizem duas entrevistas cada.

Os critérios estabelecidos para inclusão dos entrevistados são os seguintes: ser professor/professora da educação básica; ser empregado em escolas da rede pública dos estados ou municípios de abrangência dos polos de Educação a Distância da ULBRA; estar em pleno exercício da função docente; assinar o Termo de Consentimento Livre e Esclarecido (TCLE). Como critérios de exclusão, estipulou-se: ser professor contratado ou não ser concursado na rede pública dos estados ou municípios de abrangência dos polos de Educação a Distância da ULBRA; não exercer funções docentes na educação básica; não estar no pleno exercício das suas funções docentes; recusar-se a assinar o Termo de Consentimento Livre e Esclarecido (TCLE).

Uma das exigências para a realização de projetos envolvendo seres humanos é a submissão destes a um Comitê de Ética em Pesquisa. Entre os critérios de análise, está a questão do risco a que os participantes da pesquisa são submetidos quando aceitam dela participar. Em relação ao nosso projeto, a pesquisa a ser desenvolvida foi considerada com risco mínimo, uma vez que se limita ao emprego de técnicas e métodos retrospectivos, tais como questionários e entrevistas, sem qualquer tipo de intervenção fisiológica, psicológica ou social sobre os indivíduos que participam no estudo. Portanto, os riscos são aqueles inerentes à vida cotidiana. Ainda assim, submetemos o 
projeto ao Comitê de Ética em Pesquisa da Universidade.

Levando-se em consideração os aspectos éticos inerentes à pesquisa científica, as entrevistas deverão ser previamente agendadas e realizadas no lugar onde o entrevistado desejar, que não interfira em sua rotina de trabalho. Os entrevistadores são informados no momento de adesão ao projeto que, quando do início das entrevistas, deverão manter o pesquisador responsável informado sobre o andamento destas, agindo sempre no sentido de salvaguardar os direitos dos entrevistados, contribuindo para a dignidade dos seres humanos em conformidade com a legislação brasileira regulamentada pela Comissão Nacional de Ética em Pesquisa (CONEP). Da mesma forma, será o procedimento em relação ao entrevistado, sendo ele informado sobre o objetivo da pesquisa, o monitoramento e a segurança dos dados. Estes dados serão apresentados no Termo de Consentimento Livre e Esclarecido (TCLE) a ser entregue a cada um dos participantes. São ainda advertidos de que as informações por eles concedidas serão utilizadas para a pesquisa em questão, apresentadas em artigos científicos e textos de livros. Nome e demais informações pessoais capazes de identificar os entrevistados serão mantidas em sigilo.

As entrevistas, bem como as transcrições, serão armazenadas em suporte digital e farão parte de Banco de Dados, sob a responsabilidade do pesquisador responsável, podendo ser acessado para novas análises, sempre observando o disposto no Termo de Consentimento Livre e Esclarecido (TCLE).

Em relação aos possíveis benefícios aos participantes, destacamos a questão da satisfação pessoal por terem prestado serviço à comunidade escolar, no sentido de auxiliar na reconstrução de sua trajetória histórica. Também destacamos a valorização, o protagonismo e a memória dos entrevistados na construção da identidade, da unidade do grupo e da sua autoestima.

$\mathrm{Na}$ qualidade de pesquisador responsável, propusemos desenvolver junto aos estudantes/pesquisadores um processo contínuo de acompanhamento do trabalho realizado através de relatórios quinzenais em que são evidenciadas as ações inerentes à pesquisa. Ao longo do projeto, são realizadas diferentes etapas de formação e capacitação do grupo de estudantes/pesquisadores, a fim de viabilizar e promover novos conhecimentos que auxiliem no processo da pesquisa.

Para a execução do projeto, foi proposto um cronograma prevendo a submissão do mesmo ao Comitê de Ética em Pesquisa (CEP) da Universidade, além de um prazo para possíveis adequações recomendadas em pareceres emitidos polo referido Comitê. Assim, passamos a promover uma ampla divulgação do projeto através do Ambiente 
Virtual de Ensino (AVA), bem como por intermédio de outros recursos digitais capazes de levar as informações preliminares do projeto aos possíveis interessados. Uma vez selecionados e cadastrados os estudantes/pesquisadores que desejavam fazer parte do projeto, propusemos dar início ao estudo do mesmo, a fim de sanar quaisquer dúvidas referentes à sua proposição. O passo seguinte foi o de revisão de literatura a respeito do tema, além de uma etapa teórico-prática de formação e capacitação onde foram abordados os aspectos teóricos e metodológicos envolvendo a pesquisa sobre história de vida.

Uma vez concluído este primeiro ciclo formativo, demos início à localização e identificação dos entrevistados, a fim de realizarmos os primeiros contatos e lhes apresentamos o projeto. Nesta oportunidade, iremos propor que seja feito o agendamento para a aplicação do instrumento de pesquisa conforme a disponibilidade de cada um dos professores participantes. Esta etapa de entrevistas será desenvolvida após o parecer final de aprovação do projeto junto ao Comitê de Ética em Pesquisa (CEP) da Universidade, uma vez que não é possível darmos início a elas antes da tramitação do mesmo, sob pena de inviabilizarmos o projeto como um todo. Na etapa seguinte, depois de serem realizadas as entrevistas, realizaremos a transcrição do material apurado, a fim de termos como produto final os textos que irão nos subsidiar na produção de materiais diversos, tais como banners, artigos científicos e capítulos de livros destinados à apresentação e à divulgação dos resultados da pesquisa.

Neste momento, todas as etapas anteriores à realização da entrevista junto aos professores selecionados já foram desenvolvidas e o projeto encontra-se sob apreciação do Comitê de Ética em Pesquisa (CEP), para que, posteriormente, possamos dar continuidade ao trabalho.

\section{CONSIDERAÇÕES FINAIS}

Por mais que tenhamos demonstrado que a trajetória do ensino a distância vem percorrendo um caminho relativamente longo, foi a partir da incorporação das Novas Tecnologias de Informação e Comunicação associadas à generalização da informática que as instituições de ensino superior passaram a promover esta modalidade de ensino, por meio da oferta de cursos de diferentes categorias, alavancando o projeto de crescimento e expansão do ensino superior no Brasil. Ao analisarmos os dados apresentados em documentos que verificam o cenário do ensino superior no Brasil e em especial aqueles referentes ao desenvolvimento da oferta e a situação atual da educação 
a distância no país, pudemos constatar o potencial desta modalidade de ensino no processo de democratização da educação, especialmente por tudo aquilo que ela representa em termos de flexibilização do tempo de estudo e de redução de custos associada a sua ampla interiorização, em grande parte do território nacional.

Contudo, existem dilemas a serem enfrentados pela educação a distância no País. Garantir a qualidade do ensino oferecido através de profissionais qualificados além de uma infraestrutura adequada e condizente com as especificidades formativas de cada Curso e área do conhecimento são alguns dos critérios mais relevantes no âmbito da oferta dos Cursos em nível superior. Soma-se a isso a necessidade de processos avaliativos abrangentes, capazes de incorporar todos os segmentos da comunidade acadêmica, com o intuito de qualificar os processos inerentes à formação universitária, garantindo, inclusive, a redução do número de evasões e, concomitante a isso, consolidando e ampliando os índices de alunos formados nesta modalidade de ensino.

Garantir à educação a distância a equiparação em termos de excelência acadêmica frente aos cursos oferecidos na modalidade presencial talvez seja um dos maiores desafios impostos neste momento. Neste sentido, as IES vêm trabalhando no aprimoramento dos recursos humanos através de capacitações e formações voltadas à implementação de metodologias de ensino que melhor atinjam o público em questão, assim como através do desenvolvimento e aperfeiçoamento de novos e mais adequados ambientes de ensino capazes de subsidiar as práticas de professores e estudantes de modo a garantir a adequação dos meios às necessidades formativas nas diferentes áreas do conhecimento.

Outro ponto crucial neste processo é o de garantir aos estudantes universitários uma formação ampla e consistente, capaz de lhes fornecer os conhecimentos suficientes para a sua colocação no mercado de trabalho, de modo que possam assumir os diferentes desafios impostos pelas rápidas transformações por que vem passado a sociedade atual, marcada pela rapidez dos processos, especialmente aqueles ligados às novas formas de difusão e incorporação de conhecimentos. Neste sentido, não basta uma formação voltada exclusivamente ao ensino dos conteúdos consagrados na área em que se propõe a formação do estudante, é necessário que, junto a eles, sejam ampliados os horizontes do conhecimento através de atividades paralelas capazes de complementar o processo formativo, dando luz a novas formas de perceber e interpretar as situações que lhes são apresentadas no ambiente universitário. Logo, o desenvolvimento da pesquisa acadêmica aparece como um destes locais por excelência 
em que se pode abrir um leque de possibilidades em termos de preparação e formação para as novas demandas da sociedade.

Neste contexto, foi que propusemos o projeto de pesquisa História de vida e autoformação: os profissionais da educação básica e as narrativas de si, como parte da proposta de fomento à pesquisa do Curso de História, mas também como possibilidade de trabalho e aprendizagem oferecida aos acadêmicos dos demais Cursos de Licenciatura na modalidade a distância da IES. Nossa crença de que o ambiente universitário é por excelência um local de trocas e promoção de novos conhecimentos associada à necessidade da oferta da pesquisa acadêmica nesta modalidade de ensino possibilitou que, no ano de 2017, acontecesse a adesão de dezenas de alunos de diferentes cursos e de diversas partes do Brasil envolvidos em um trabalho conjunto de pesquisa e conhecimento da profissão docente. No ano de 2018, após a aprovação do projeto de pesquisa junto ao Comitê de Ética em Pesquisa (CEP) da IES, daremos início ao trabalho em campo, realizando entrevistas que, depois de transcritas, servirão como base para a nossa produção textual. Será mais um momento privilegiado em que teremos acesso a novos conhecimentos, ao autoconhecimento, às trocas, às confirmações e ao estreitamento dos laços que fazem, de cada um de nós, alunos, pesquisadores e professores.

Recebido em: 31-01-2018 Aceito em: 21-06-2018

\section{REFERÊNCIAS}

ALVES, Lucineia. Educação a distância: conceitos e história no Brasil e no mundo. RBAAD - Associação Brasileira de Educação à Distância, vol. 10, 2011. p. 83-92. Disponível em:

http://www.abed.org.br/revistacientifica/Revista_PDF_Doc/2011/Artigo_07.pdf. Acesso em: 14 dez. 2017.

Basso, Rosângela Aparecida Alves; Prado, Márcio Roberto do - Universidade Aberta do Brasil: política de democratização e interiorização da educação superior pública a distância no Brasil. In Colóquio Luso-Brasileiro de Educação a Distância e Elearning, Lisboa, 2013. "Colóquio Luso-Brasileiro...: atas". Lisboa: Universidade Aberta. LEAD, 2014. p. 1-14. Disponível em: https://repositorioaberto.uab.pt/bitstream/10400.2/2986/1/ Universidade\%20aberta\%20do\%20brasil.pdf. Acesso em: 13/04/2017.

BRASIL. Lei n ${ }^{\circ}$ 9.394, de 20 de dezembro de 1996. Estabelece as diretrizes e bases da educação nacional. Lei de Diretrizes e Bases da Educação-LDB. Brasília, DF, 1996. Disponível em: http://www.planalto.gov.br/ccivil_03/leis/19394.htm. Acesso em: 14 dez. 2017. 
Brasil. Ministério do Planejamento, Orçamento e Gestão. Síntese de Indicadores Sociais: Uma análise das condições de vida da população brasileira. Estudos e Pesquisas Informação Demográfica e Socioeconômica, número 34. Instituto Brasileiro de Geografia e Estatística - IBGE, 2014. Disponível em: https://biblioteca.ibge.gov.br/visualizacao/livros/liv91983.pdf. Acesso em: 20/04/2017.

Censo da Educação Superior 2016, Notas estatísticas. Ministério da Educação - Instituto Nacional de Estudos e Pesquisas Educacionais Anísio Teixeira, 2017. Disponível em: http://download.inep.gov.br/educacao_superior/censo_superior/documentos/2016/notas_s obre_o_censo_da_educacao_superior_2016.pdf. Acesso em: 4 jan. 2018.

Censo EAD.BR: relatório analítico da aprendizagem a distância no Brasil 2016. ABED - Associação Brasileira de Educação a Distância. Curitiba: InterSaberes, 2017. Disponível em: http://abed.org.br/censoead2016/Censo_EAD_2016_portugues.pdf. Acesso em: 4 jan. 2018.

COSTA, Celso José da: PIMENTEL, Nara Maria. O Sistema Universidade Aberta do Brasil na consolidação da oferta de Cursos superiores a distância no Brasil. ETD Educação Temática Digital, Campinas, v.10, n.2, jun, 2009. p.71-90. Disponível em: https://periodicos.sbu.unicamp.br/ojs/index.php/etd/article/view/978/993. Acesso em: 25/03/2017.

Costa, L. A. C. e Franco, S. R.K. Ambientes Virtuais De Aprendizagem e suas Possibilidades Construtivistas. Revista Novas Tecnologias na Educação, v. 3, n. 1. Maio, 2005. p. 1-10. Disponível em:

http://seer.ufrgs.br/index.php/renote/article/view/13781/7972. Acesso em: 22/04/2017.

GOLDIM, José Roberto. Projeto de Pesquisa: Aspectos Éticos e Metodológicos. Disponível em: https://www.ufrgs.br/bioetica/projeto.htm. Acesso em: 23 out. 2016.

HERMIDA, Jorge Fernando; BONFIM, Cláudia Ramos de Souza. A EAD: História, Concepções e Perspectivas. Revista Histedbr on-line, Campinas, número especial, p. 166-181, 2006. Disponível:

http://www.histedbr.fe.unicamp.br/revista/edicoes/22e/art11_22e.pdf. Acesso em: 15 dez. 2017.

HERNANDES, Paulo Romualdo. A Universidade Aberta do Brasil e a democratização do Ensino Superior público. Ensaio: aval. pol. públ. Educ., Rio de Janeiro, v. 25, n. 95, p. 283-307. Disponível em: http://www.scielo.br/pdf/ensaio/v25n95/1809-4465-ensaioS0104-40362017002500777.pdf. Acesso em: 22/03/2017.

JOSSO, Marie-Christine. Os relatos de histórias de vida como desvelamento dos desafios existenciais da formação e do conhecimento: destinos socioculturais e projetos de vida programados na invenção de si. In: SOUZA, Elizeu Clementino de; ABRAHÃO, Maria Helena Menna Barreto (orgs.). Tempos, narrativas e ficções: a invenção de si. Porto Alegre: EDIPUCRS, 2006.

MORAES, Roque; GALIAZZI, Maria do Carmo. Análise textual discursiva. Ijuí: Ed. Unijuí, 2007. 
NOVOA, Antônio. Formação de professores e profissão docente. In: António Nóvoa (Coord.). Os professores e a sua formação. Lisboa: Publicações Dom Quixote, 1992. p. 13-33.

OECD (2015), "Brazil", in Education at a Glance 2015: OECD Indicators. Instituto Nacional de Estudos e Pesquisas Educacionais - INEP, Brasil para essa edição em língua portuguesa. p. 1-10. Disponível em: https://www.oecd.org/brazil/Education-at-aglance-2015-Brazil-in-Portuguese.pdf. Acesso em: 22/04/2017.

PEREIRA, Lourivaldo dos Santos Souza Aragão; FRANÇA, George. Os ambientes virtuais de aprendizagem (AVA): um estudo do moodle no curso de pedagogia da UFT.Revista InterSciencePlace, Edição 25, v. 1, artigo n 5, Abril/Junho 2013. p. 77-92. Disponível em: http://www.interscienceplace.org/isp/index.php/isp/article/view/240/237. Acesso em: 24/04/2017.

Plano de Desenvolvimento Institucional - PDI/ULBRA. Canoas: ULBRA, 2017.

Projeto Pedagógico do Curso de História EAD - PPC História EAD/ULBRA. Canoas: ULBRA, 2016.

Plano Pedagógico Institucional - PPI/ULBRA. Canoas: ULBRA, 2015.

SEGOVIA, Jesús Domingo. La teoría fundamentada del profesorado desde un enfoque biográfico-narrativo. Fundamentación, processos y herramientas. In: ABRAHÃO, Maria Helena Menaa Barreto; BOLIVAR, Antonio (orgs.). La investigación (auto) biográfica en educacion: miradas cruzadas entre Brasil y España. Granada: EUG; Porto Alegre: EDIPUCRS, 2014. p. 110-141

SILVA, Tomaz Tadeu da. O currículo como Fetiche: a poética e a política do exto curricular. Belo Horizonte: Autêntica, 2006.

TARDIF, Maurice; LESSARD, Claude; GAUTHIER, Clermont. Formação dos professores e contextos sociais. Porto, PT: Rés Editora, 2000.

. Saberes docentes e formação profissional. Petrópolis, RJ: Vozes, 2002.

. LESSARD, Claude. O trabalho docente. Petrópolis: Vozes, 2007. 